\title{
Пастухова Д.А.
}

\section{КУЛЬТУРНО ОБУСЛОВЛЕННЫЕ ОСОБЕННОСТИ ОБЩЕНИЯ} В ПРОЦЕССЕ МЕЖКУЛЬТУРНОЙ КОММУНИКАЦИИ

доцент, кандидат психологических наук. Московский государственный областной университет, ул. Веры Волошиной, 24, г. Мытищи, 141014, Россия. E-mail: PastukhovaD @mail.ru

\begin{abstract}
Аннотация. Статья посвящена проблеме улучшения межкультурной коммуникации в условиях современного информационного общества. Рассмотрены теоретические подходы к изучению культурно обусловленных особенностей общения в процессе межкультурной коммуникации. Обосновано влияние культуры на общение в процессе межкультурной коммуникации. Определены понятие коммуникации с позиций информационного подхода и роль современных информационно-коммуникационных технологий в процессе становления личности и осуществления коммуникации. Дана характеристика основных факторов, оказывающих влияние на процесс межкультурной коммуникации. Обозначена проблема политической корректности как явления современной общественной, политической и культурной жизни. Представлены характеристики коммуникативного поведения англичан и россиян, выявлены их сходства и различия.
\end{abstract}

Ключевые слова: культура, общение, межкультурная коммуникация, факторы межкультурной коммуникации, политическая корректность, особенности общения русских и англичан.

UDK 339.9.012

DOI: 10.18413/2408-9346-2016-2-2-39-44

Pastukhova D.A.

CULTURAL FEATURES OF COMMUNICATION IN THE INTERCULTURAL DIALOGUE

Associate Professor, PhD in Psychology. Moscow State Regional University,

24 Very Voloshinoy St., Mytischi, 141014, Russia. E-mail: PastukhovaD@mail.ru

\begin{abstract}
The article deals with the problem of improving cross-cultural communication in the modern information society. Theoretical approaches to the study of the cultural features of communication in the process of intercultural communication are considered. The influence of culture on communication in the process of intercultural dialogue is justified. The concept of communication based on the position of information approach and the role of modern information and communication technologies in the process of identity formation and implementation of communication are defined. The characteristics of the main factors influencing the process of intercultural dialogue are given. The problem of political correctness as a phenomenon of contemporary social, political and cultural life is indicated. The features of communicative behavior of the British and the Russians are presented, their similarities and differences are revealed.
\end{abstract}

Key words: culture; communication; intercultural dialogue; intercultural dialogue factors; political correctness; features of communication between the Russian and English.

В связи со становлением информационного общества многократно прогнозировалась гармонизация межнациональных отношений на основе улучшения межкультурного обмена в связи с развитием электронных средств массовой информации и коммуникации (СМИК). Однако в течение последних лет, несмотря на всеобщий консенсус относительно уже якобы сформировавшегося информационного общества, эти отношения последовательно обостряются [см., например, 17]. Это определяет несомненную актуальность исследований проблем межкультурной коммуникации.

Объектом настоящего исследования являются национально-культурные особенности общения англичан и русских. Предметом изучения выступают культурно обусловленные особенности общения.

Целью исследования является изучение культурно обусловленных особенностей общения в процессе межкультурной деловой коммуникации. 
Для достижения данной цели были поставлены задачи:

1) рассмотреть теоретические подходы к изучению культурно обусловленных особенностей общения в процессе межкультурной коммуникации;

2) обозначить влияние культуры на общение в процессе межкультурной коммуникации;

3) исследовать современные тенденции языковой политики Великобритании;

4) представить характеристику коммуникативного поведения англичан и россиян;

5) описать сходства и различия характеристик коммуникативного поведения россиян и англичан.

Для реализации поставленных задач использовались: прием контекстного анализа, прием интерпретации, направленный на определение содержания исследуемого явления. Также использовались аналитический и сравнительно-сопоставительный методы.

Теоретическую базу исследования составили труды ведущих отечественных и зарубежных ученых по проблемам межкультурной коммуникации:

- теории межкультурной коммуникации (А. П. Садохин, С. Г. Тер-Минасова);

- теории языковой

личности

(В. В. Виноградов, В. И. Карасик);

- исследования в области антропологии и социологии (Е. Hall).

В настоящее время отмечается повышение исследовательского интереса к проблемам межкультурной коммуникации. Судя по контексту, в котором чаще всего в соответствующих работах употребляется термин «коммуникация», большинство авторов понимают под ней взаимодействие культур, если вообще не их сотрудничество. В целом коммуникацию определяют как передачу сигналов, информации и их прием; представляют как обмен информацией различного содержания, передаваемой при помощи различных средств с целью достижения взаимопонимания.

В отношении межкультурной коммуникации доминирует точка зрения, в соответствии с которой ее участники являются представителями разных культур и осознают культурные явления, не соответствующие их культуре, как чужие, относятся к различным лингвокультурным сообществам и т.п.

Что касается термина «культура», то существует целый ряд ее теорий и, по разным подсчетам, более 400 ее определений, хотя многие из них весьма схожи. Кратко отметим, что со времен древних римлян, когда слово «культура» (cultura) было введено в оборот, под ним понималось противопоставление слову «природа» (natura), как культивирование в значении возделывание, выращивание чего-либо, поначалу растений, почвы и постепенно - души, ума. В современной западной культурологии и социальной антропологии культуры понимаются как адаптивно-адаптирующие системы, обеспечивающие устойчивые в историческом времени стратегии физического и духовного выживания той или иной популяции [12].

Наиболее модная и во многих случаях главная политическая позиция последних лет мультикультурализм - основана на философии постмодернизма, который провозглашает ценность всех культур, их равенство, которое, в свою очередь, ведет их ко взаимному обогащению [7]. Кроме этого, считается, что все культуры представляют собой некоторую целостность, а их особенности не противоречат общечеловеческим ценностям.

В настоящем исследовании мы будем придерживаться следующего рабочего определения: культура - это результат психического развития группы индивидов в процессе их коллективной деятельности по приспособлению к среде в виде информационной системы, создаваемой в индивидуальных сознаниях и разделяемой членами конкретного общества на основе определенной системы ценностей, обеспечивающей выживание, жизнедеятельность и воспроизводство каждого конкретного общества как совокупности членовносителей его информационной системы (культуры) при смене поколений [1].

Важно также пояснить родственное понятие субкультура. С вышеизложенной точки зрения ее отличие от культуры состоит в том, что субкультура, во-первых, не содержит набора информации, достаточного для самостоятельной жизнедеятельности, поэтому не может существовать без базиса, «несущей волны» какойлибо культуры, и, во-вторых, ее информационная система может, в отличие от культурной, ограничиваться любым набором компонентов или даже одним из них (например, субкультура любителей здорового питания или поклонников какого-либо певца), т.е. быть абсолютно субъективным феноменом без связи с другими членами общества и даже с объективной реальностью [8].

С точки зрения информационного подхода коммуникация вообще представляет собой лишь 
передачу некоторых смысловых сигналов с различным исходом их получения, понимания и использования адресатом - т.е. социальной системой ценностей, закрепленной в информационном содержании его сознания и которой он, как член соответствующего общества, придерживается в своей жизнедеятельности [3].

Это позволяет по-новому посмотреть на происходящие сегодня процессы, причем не только между, например, европейскими и исламскими культурами, которые сегодня в центре внимания, но и внутри них. Тогда выясняется, что определение носителя любой культуры - это не просто выяснение его религиозной, этнической, расовой или тем более генетической характеристики.

В современную эпоху, характеризуемую значительным развитием электронных средств массовой информации и коммуникации, существенно изменился процесс формирования каждой личности, понимаемый как становление, развитие и функционирование информационного содержания его сознания. Это по-прежнему информационный процесс, но осуществляется он теперь иначе, и связано это с новой ролью и местом современных информационнокоммуникационных технологий (ИКТ) в процессе формирования каждой личности [5].

Ранее действительно место и страна рождения, национальность, религиознокультурная принадлежность и, наконец, гражданство были определяющими факторами для судьбы человека. В условиях доиндустриальной эпохи воспитание детей и юношества происходило в рамках их практически тотальной вовлеченности в жизнь своих семей и общин. С началом расцвета первых печатных СМИК и с внедрением повсеместно начального школьного образования, т.е. примерно с середины XIX века, несемейные факторы стали оказывать все более существенное влияние на становление и социализацию новых членов общества [6].

Сегодня, в эпоху электронных средств информации и коммуникации, формирование каждого нового человека и новых сообществ имеет не столь сильную связь со своим антропологическим (родительским, семейным) первоначалом и в значительной степени определяется его (их) вовлеченностью в информационные процессы. Формирование личности все более обусловливается степенью активности прямых или опосредованных через различные электронные коммуникации информационных контактов [2].

На процесс межкультурной коммуникации оказывают влияние следующие основные факторы:

- факторы среды;

- культурные факторы;

- социальные факторы;

- психологические факторы.

Факторы среды - это «силы, создающие и поддерживающие культурные различия» [15]. К ним относят историю данного сообщества, географические и климатические условия, особенности вероисповедания, используемые технологии, трудовые практики, особенности социально-трудовой сферы и др. [4].

Культурные факторы. Данные факторы проявляют себя в явной и неявной форме. К числу первых можно отнести, например, предметы интерьера, одежды, кулинарные традиции и т.п. В неявной форме проявляют себя ценности, принципы, стереотипы, которые существуют в сознании людей, определяют принятые в сообществе модели поведения. По мнению исследователей, данные культурные модели оказывают самое сильное влияние на коммуникативное поведение людей [16].

Cоциальные факторы, обуславливающие процесс межкультурной коммуникации, связаны с принадлежностью участников коммуникации к различным общественным группам, осознанием ими своих ролей и статусов в этих группах.

Психологические факторы в процессе межкультурной коммуникации определяются теми внутренними психологическими процессами участников взаимодействия, которые создают у них чувство психологического комфорта или дскомфорта. К числу этих факторов относят мотивационную направленность индивидов [9], их ожидания по поводу возможной реакции на их действия представителей иных культур и др.

Более 30 лет политическая корректность как явление общественной, политической, культурной жизни многих англоговорящих стран не только служит предметом изучения лингвистов, историков, социологов, философов, но и вызывает живой интерес у общества, о чем свидетельствуют бурные дискуссии в средствах массовой информации.

Следует отметить, что за все прошедшие годы не было выработано общепринятого определения политической корректности. Довольно часто под политической корректностью 
понимается «стремление найти новые способы языкового выражения взамен тех, которые задевают чувства и достоинство индивидуума, ущемляют его человеческие права привычной языковой бестактностью и/или прямолинейностью в отношении расовой и половой принадлежности, возраста, состояния здоровья, социального статуса, внешнего вида и т.п.» [15].

Политическая корректность давно перешагнула границы англоязычного мира. Современные сторонники политической корректности больше не удовлетворяются пересмотром отдельных слов и терминов. В последнее десятилетие на повестку дня встал вопрос о так называемом «инклюзивном языке» (inclusive language). Среди его основных правил можно выделить следующие:

- не подчеркивать пол, расовую принадлежность, национальность или другие особенности человека (например, сексуальную ориентацию, возраст, инвалидность) в том, случае, когда они не имеют непосредственного отношения к предмету разговора;

- не выделять людей по их национальному признаку, если они являются представителями единственного национального меньшинства в данной группе.

Рекомендуются, например, следующие замены:

housewife $\rightarrow$ homemaker, house spouse, parent, caregiver; actress $\rightarrow$ actor, performer; brotherhood $\rightarrow$ community, unity; Founding Fathers $\rightarrow$ the founders, pioneers; policeman $\rightarrow$ police officer [14].

C 90-х годов XX века выпускаются многочисленные пособия по написанию политически корректных текстов. Использование инклюзивного языка становится обязательным во многих университетах и других учебных заведениях [13].

Деловое общение англичан и россиян имеет следующие особенности. Англичане очень консервативны, стремятся придерживаться установленных формальных процедур и правил. Вместе с тем, они охотно обращаются к юмору, когда надо снять лишнее напряжение. Если в начале коммуникации они ведут себя довольно сдержанно, то в последующем используют более раскованные модели поведения. При установлении контакта с англичанами большое значение имеет проявление доброго, уважительного отношения к их ценностям и идеалам. Англичане умеют терпеливо слушать собеседника, что не обязательно означает согласие с его позицией, в то же время они негативно оценивают многословие и активные попытки навязывания собеседником своего мнения. Также они могут искусно использовать личное обаяние, непринужденность и доброжелательность, проявляя в принципиальных вопросах достаточную жесткость. Во взаимоотношениях они ориентируются, скорее, на долгосрочную перспективу, нежели чем на текущий момент.

В общении англичане избегают категорических утверждений, проявляют достаточную гибкость, пытаются найти решение, устраивающее обе стороны. Существенными аргументами для принятия компромиссных решений англичане считают репутацию, уровень ресурсов и поддержки, которыми располагают оппоненты. В переговорах английские бизнесмены демонстрируют высокий уровень профессионализма и практицизма.

Русский характер и менталитет складывался изначально под влиянием многих факторов, к числу которых следует отнести православие как основную систему вероисповедания, суровость климата, обширность и малозаселенность территории, общинность и др. Серьезный отпечаток на российский стиль общения наложил период социалистического строительства, когда идеологические установки, определенные центральной властью, господствовали в обществе. Впрочем, не следует умалять и сильных сторон, принадлежавших прежней советской школе.

К характерным чертам русских исследователи относят умеренный коллективизм, готовность к самопожертвованию, мобилизационный тип жизнедеятельности, способность стойко переносить невзгоды, упорство, вольность, пренебрежение к закону, душевность, отзывчивость $[10,11]$.

В процессе коммуникации россияне, как правило, четко обозначают свои позиции по обсуждаемому вопросу и проявляют значительную настойчивость в ее отстаивании, используя разнообразные приемы для получения выигрышных позиций. С другой стороны, они проявляют стремление к дружескому, неформальному общению. Некоторая подозрительность и скептицизм также часто отмечаются как традиционные черты коммуникации русских.

Как отмечают английские бизнесмены, в процессе переговоров россияне используют концептуальный подход к решению проблем, уделяя большое внимание глобальным, общим 
целям, в то время как, например, американцы и немцы уделяют значительное внимание деталям и тонкостям рассматриваемых вопросов. Другой отмечаемой особенностью российских бизнесменов является способность принимать на себя риск и интуитивно чувствовать партнера, что часто дает им весомые преимущества, как и готовность к бескорыстной помощи, создающей атмосферу доверия.

Указанные черты россиян, проявляющиеся в процессе коммуникации, во многом являются традиционными, хотя и подвергаются некоторой трансформации благодаря процессам глобализации и интернационализации, являющимися характерным признаком современности.

При всех различиях коммуникативного поведения россиян и англичан можно выделить и некоторые моменты, обнаруживающие сходство.

Во-первых, это проявляется в английском стоицизме, который близок русскому фатализму, что отражается в приверженности тех и других к духовным, интеллектуальным ценностям, в противовес ценностям чисто материального характера.

Во-вторых, объединяющим началом в коммуникативном процессе служит, с одной стороны, сдержанность, проявляемая англичанами и скептицизм, характерный для русских.

Наконец, и для русских, и для англичан, особенно если это касается первого знакомства, требуется некоторе время для того, чтобы ослабить напряжение, перейти к более комфортным формам общения.

К числу несовпадающих характеристик коммуникативного поведения россиян и англичан можно отнести следующие.

Во-первых, россиянам присуща приверженность к большим масштабам. Они часто руководствуются принципом «чем больше, тем лучше», упуская детали и жертвуя качеством. У англичан более правильным подходом считается принцип «лучше меньше, да лучше».

Во-вторых, россияне, по большей части, проявляют коллективистские начала, терпимо относятся к сокращению своего личного пространства, в то время как в основе английской культуры лежит индивидуализм. Англичане склонны оберегать свое личное пространство, вторжение в личную жизнь рассматривают как посягательство на права личности.

Наконец, значительные отличия имеет эмоциональный контекст общения русских и англичан. Английская культура относится к нейтральным. Следствием этого является общеизвестная английская сдержанность. Русская культура, напротив, проявляет себя как эмоциональная, поэтому россиянам присуща экспрессия, а иногда и эмоциональная невыдержанность. Одним из проявлений данного различия является то обстоятельство, что англичане обычно крайне сдержанны в оценках как своих заслуг, так и своих проблем. Что касается россиян, то они часто склонны к подчеркиванию и того, и другого, особенно при наличии внимания собеседника к данным аспектам. Категоричность суждений, присущая нашим соотечественникам, как и неприятие таковой англичанами, также являются следствием указанного несоответствия коммуникативных характеристик русских и англичан.

\section{Список литературы}

1. Емельянов, Ю. Н., Скворцов, Н. Г. Культуральная антропология. СПб., 1996.

2. Енгибарян, Р. С чего начинается личность // Независимая газета. 2011.

3. Захарова, Н. Л., Ядров, К. П., Мельников, Т. Н. Особенности инновационного знания // Человеческий фактор: проблемы психологии и эргономики. 2015. № 2 (73). С. 35-37.

4. Игнатова, Т. В., Слинков, А. М. Использование методологического потенциала дефинициальной характеристики социально-трудовой сферы в развитии мониторинговых функций управления персоналом организаций // Вестник Адыгейского государственного университета. Серия 5: Экономика. 2015. № 4 (170). С. 267-273.

5. Копнина, Г. А. Речевое манипулирование. М.: Флинта Наука, 2007.

6. Люсый, А. Переводы: пришествие новых смыслов // Космополис. М., 2003. № 2 (4). С. 49-63.

7. Лютова, С. Н. Основы психологии и коммуникативной компетентности: Курс лекций. М.: МГИМО-Университет, 2007.

8. Пастухова, Д. А., Грудистова, Е. Г. European credit system of education // Научный результат. Серия: Технология бизнеса и сервиса. 2015. Т.1. № 3 (5). C. 30-36.

9. Слинков, А. М. Труд - потребность инновация: управленческий и мотивационный аспект // Социально-гуманитарные знания. 2014. № 8 . C. $318-327$.

10. Слинкова, О. К., Пастухова, Д. А. Национально-психологические особенности персонала российских организаций // Научный результат. Серия: Технологии бизнеса и сервиса. 2014. № 2 (2). С. 85-91.

11. Слинкова, О. К. Трудовая мотивация и организационная культура (теоретикометодологические и прикладные основы 
исследования) / О. К. Слинкова // Диссертация на соискание ученой степени доктора экономических наук / Кемерово, 2006. 331 с.

12. Табакова, И. А., Пастухова, Д. А. Мотивационная структура адаптивной личности // Труды Братского государственного университета. Серия: Гуманитарные и социальные науки. 2008. № 1. C. $56-60$

13. Ядров, К. П. Генезис инноватики: от организации к индивидууму// Человеческий капитал. 2015. № 4 (76). С. 120-124.

14. Do's and Don'ts of Inclusive Language. Media Task Force. Honolulu, 1998.

15. Lustig, M. W. Intercultural competence: Interpersonal communication across cultures / M.W. Lustig, J.Koester. $3^{\text {rd }}$ ed. New York, NY: Longman, 1999. $401 \mathrm{p}$.

16. Samovar, L. A. Communication between cultures / L. A. Samovar, R. E. Porter. $4^{\text {th }}$ ed. Belmont, CA: Wadsworth, 2001. 334 p.

17. Slinkova, O. K. Globalization of the economy and socio-cultural // Научный результат. Серия: Технологии бизнеса и сервиса. 2015. № 4(6). С. 29-32.

\section{References}

1. Emelyanov, Y. N., Skvortsov, N. G. The Culture Anthropology. St. Petersburg., 1996.

2. Engibaryan, R. What a re the Origins of Personality // Nezavisimaya Gazeta. 2011.

3. Zakharova, N. L., Yadrov, K. P., Melnikov, T. N. Features of Innovative Knowledge // The Human Factor: the Problem of Psychology and Ergonomics. 2015. Number 2 (73). Pp. 35-37.

4. Ignatova, T. V., Slinkov, A. M. Using the Methodological Potential Definitional Characteristics of the Social and Labor Sphere in the Development of the Monitoring Functions of Human Resource Management Organizations // Herald of Adygeya State University. Series 5: The Economy. 2015. 4 Number (170). Pp. 267-273.

5. Kopnina, G. A. Speech Manipulation. Moscow: Flint Science, 2007.

6. Lyusy A. Translations: Coming of new Meanings // Cosmopolis. Moscow, 2003. № 2 (4). Pp. 49-63.
7. Lyutova, S. N. Fundamentals of Psychology and Communicative Competence: Lectures. Moscow: MGIMO-University, 2007.

8. Pastukhova, D. A., Grudistova E. G. European Credit System of Education // The Scientific Result. Series: Business Technology and Service. 2015. Vol.1. № 3 (5). Pp. 30-36.

9. Slinkov, A. M. Work - Need - Innovation: Management and Motivational Aspect // Sociallyhumanitarian knowledge. 2014. № 8. Pp. 318-327.

10. Slinkova, O. K., Pastukhova, D. A. Nationalpsychological Features of the Russian Joint Staff // The Scientific Result. Series: Business Technology and Service. 2014. № 2 (2). Pp. 85-91.

11. Slinkov,a O. K. Work Motivation and Organizational Culture (theoretical and methodological foundations and applied research). Slinkova O.K. Doctoral thesis for the degree of Doctor of Economic Sciences / Kemerovo, 2006. $331 \mathrm{p}$.

12. Tabakova, I. A., Pastukhova, D. A. Motivational Structure of Adaptive Personality // Proceedings of Bratsk State University. Series: Humanities and Social Sciences. 2008. № 1. Pp. 56-60.

13. Yadrov, K. P. The Genesis of Innovation: from the Organization to the Individual // Human Capital. Number 2015. 4 (76). Pp. 120-124.

14.Do's and Don'ts of Inclusive Language. Media Task Force. Honolulu, 1998.

15.Lustig, M. W. Intercultural competence: Interpersonal communication across cultures M. W. Lustig, J.Koester. $3^{\text {rd }}$ ed. New York, NY: Longman, 1999. $401 \mathrm{p}$.

16. Samovar, L. A. Communication between cultures / L.A. Samovar, R.E. Porter. $-4^{\text {th }}$ ed. - Belmont, CA: Wadsworth, 2001. $-334 \mathrm{p}$.

17. Slinkova, O. K. Globalization of the economy and socio-cultural // Scientific results. Series: Business Technology and Service. 2015. Number 4 (6). Pp. 29-32.

\section{Рецензент}

Слинкова О.К., доктор экономических наук, доцент профессор кафедры туризма и социально-культурного сервиса Института управления,

Белгородский государственный национальный исследовательский университет (НИУ «БелГУ»), 